NBER WORKING PAPER SERIES

\title{
PRICE LEVEL TARGETING VS. INFLATION \\ TARGETING: A FREE LUNCH?
}

Lars E. O. Svensson

Working Paper 5719

\section{NATIONAL BUREAU OF ECONOMIC RESEARCH 1050 Massachusetts Avenue \\ Cambridge, MA 02138}

August 1996

Part of the work for this paper was done during a visit to the International Finance Division at the Federal Reserve Board, Washington D.C., in July 1995. I am grateful to the Division for its hospitality. I thank George Akerlof, Alan Blinder, Guy Debelle, Jon Faust, Stanley Fischer, John Hassler, Dale Henderson, Miles Kimball, David Lebow, Frederic Mishkin, Torsten Persson, Carl Walsh and participants in seminars at the CEPR Money Workshop at IGIER, Milan, IIES, Institute for Graduate Studies, Geneva, NBER Summer Institute Monetary Economics Workshop, Tilburg University, University of California, Berkeley, and University of California, Santa Cruz, for discussions and comments. I also thank Mårten Blix for research assistance, and Maria Gil and Christina Lönnblad for secretarial and editorial assistance. Expressed views as well as any errors and obscurities are my own responsibility. This paper is part of NBER's research programs in International Finance and Macroeconomics, and Monetary Economics. Any opinions expressed are those of the author and not those of the National Bureau of Economic Research.

(C) 1996 by Lars E. O. Svensson. All rights reserved. Short sections of text, not to exceed two paragraphs, may be quoted without explicit permission provided that full credit, including $\odot$ notice, is given to the source. 


\title{
PRICE LEVEL TARGETING VS. INFLATION
}

TARGETING: A FREE LUNCH? WAGE

\begin{abstract}
Price level targeting (without base drift) and inflation targeting (with base drift) are compared under commitment and discretion, with persistence in unemployment. Price level targeting is often said to imply more short-run inflation variability and thereby more employment variability than inflation targeting. Counter to this conventional wisdom, under discretion a price level target results in lower inflation variability than an inflation target (if unemployment is at least moderately persistent). A price level target also eliminates the inflation bias under discretion and, as is well known, reduces long-term price variability. Society may be better off assigning a price level target to the central bank even if its preferences correspond to inflation targeting. A price level target thus appears to have more advantages than commonly acknowledged.
\end{abstract}

Lars E. O. Svensson

Institute for International Economic Studies

Stockholm University

S-106 91 Stockholm

SWEDEN

and NBER

Lars.Svensson@iies.su.se 


\section{Introduction}

"Price stability" is often recommended as a goal for monetary policy. Price stability has been interpreted in different ways, though. Price stability can be interpreted as price level stability, that is, a stationary price level with low variance. In practice, price stability has often been interpreted as low and stable inflation. As is well known, unless above-average inflation is followed by below-average inflation, this results in base drift of the price level. Base drift in the price level implies that the price level becomes non-trend-stationary, and the variance of the future price level increases without bounds with the forecast horizon. This is obviously rather far from literal price stability. I shall refer to a monetary policy regime as price level targeting or inflation targeting, depending upon whether the goal is a stable price level or a low and stable inflation rate, where the latter allows base drift of the price level.

In the real world, there are currently several monetary policy regimes with explicit or implicit inflation targeting (see Haldane (1995) and Leiderman and Svensson (1995)), but there are no regimes with explicit or implicit price level targeting. Whereas the Gold Standard may be interpreted as implying implicit price level targeting, Sweden during 1931-33 may so far have been the only regime in history with explicit price level targeting (cf. Fisher (1934) and Jonung (1979)).

Even if there are no current examples of price level target regimes, price level targeting has received increasing interest in the monetary policy literature, and several recent papers compare inflation targeting and price level targeting. Several papers are collected in Bank of Canada (1994). Duguay (1994) summarizes these papers and others and provides a thorough discussion of the issues involved, see also Fischer (1994) and Goodhart and Viñals (1994). Some papers compare inflation and price level targeting by simulating the effect of postulated reaction functions (Lebow, Roberts and Stockton (1992), Fillon and Tetlow (1994), Haldane and Salmon (1995)). Other papers compare the properties of postulated simple stochastic processes for inflation and the price level (Duguay (1994), Fischer (1994)). A frequent result, emerging as the conventional wisdom, is that the choice between price-level targeting and inflation targeting involves a trade-off between low-frequency price level uncertainty on the one hand and highfrequency inflation and output uncertainty on the other. ${ }^{1}$ Thus, price level targeting has the

\footnotetext{
1 The result is emphasized in Lebow, Robert and Stockton (1992), Fischer (1994), and Haldane and Salmon (1995). In contrast, Fillon \& Tetlow (1994) report that in their simulations price level targeting results in less inflation variability but in more output variability than inflation targeting. No explanation is offered beyond the observation that the results indicate strong serial correlation of the price level. Duguay (1994) does not report the unconditional variance of one-period inflation rates in his examination of different processes for inflation and the
} 
advantage of reduced long-term variability of the price level. This should be beneficial for longterm nominal contracts and intertemporal decisions, but comes at the cost of increased shortterm variability of inflation and output. The intuition is straightforward: In order to stabilize the price level under price level targeting, higher-than-average inflation must be succeeded by lowerthan-average inflation. This should result in higher inflation variability than inflation targeting, since in the latter case base level drift is accepted and higher-than-average inflation need only be succeeded by average inflation. Via nominal rigidities, the higher inflation variability should then result in higher output variability. ${ }^{2}$

Applying postulated monetary policy reaction functions, 'instrument rules', evokes the issue of whether these reaction functions are optimal for reasonable objective functions of the central bank, and whether they are consistent with the realistic situation when the central bank acts under discretion and commitment to an optimal or a simple second-best rule (like those in McCallum (1990) or Taylor (1994)) is not possible (cf. Laidler (1993)). Similarly, applying postulated processes for inflation and the price level evokes the issue of whether these are consistent with a reasonable equilibrium.

The purpose of this paper is to compare price level and inflation targeting, but the paper departs from the previous literature on price level versus inflation targeting by applying a principal-agent approach: the decision rules considered are the endogenous decision rules that result when society (the principal) assigns (delegates) an inflation target or a price level target to a central bank (the agent) acting under discretion. In comparison, the corresponding endogenous decision rules under commitment are also reported, although the focus is on the discretion case. The reaction functions are hence endogenous, given central bank objectives and constraints, including available commitment technology.

The paper follows Svensson (1996) in interpreting inflation targeting as including an explicit inflation target and an implicit employment target, with an implicit relative weight on employment stabilization. This is motivated by the existence of target bands in actual inflation targeting regimes, indicating that some short-term inflation variability may be acceptable due

price level, although for some of the parameters studied that variance is actually less under price level targeting (see the appendix to the present paper).

${ }^{2}$ Hall $(1984,1986)$ provides arguments for price stability. McCallum (1990) argues that price level targeting provides a relatively small gain in long run price predictability, since price level variability (for the U.S.) is already relatively small under inflation targeting. Gerlach (1993) interprets inflation targets as a 'target zone' for the price level. Scarth (1994), Craw ford and Dupasquier (1994), and Konieczny (1994) discuss various aspects of price targeting and inflation targeting.

Base drift in money supply is distinct from base drift in the price level. As shown by Walsh (1986), some degree of money supply base drift is warranted even with price level stability, if there are permanent shocks to money demand and output. 
to imperfect control over inflation but perhaps also in order to dampen employment fluctuations; the fact that no inflation targeting central bank seems to behave as if it wants to attain the inflation target at any cost (cf. Haldane (1995) and Leiderman and Svensson (1995)); and by wording in King (1995) that indicates that the inflation targeting Bank of England is not an "inflation nutter" with zero weight on employment stabilization. Price level targeting is consequently interpreted as including an explicit price level target, together with an implicit employment target. ${ }^{3}$

The paper considers the realistic case when output and employment is persistent. The degree of persistence in employment is indeed crucial for the results: Without persistence, a trivial trade-off between long-term price level variability and short-term inflation variability arises. With at least moderate persistence, counter to the conventional wisdom, there is no trade-off between price level variability and inflation variability. Price level targeting then results in lower inflation variability than inflation targeting. This result is due to the endogenous decision rule that results under discretion for different targets. Under inflation targeting the decision rule is a linear feed-back rule for inflation on employment. Then the variance of inflation is proportional to the variance of employment. Under price level targeting, the decision rule is a linear feed-back rule for the price level on employment. Then inflation is a linear function of the first difference of employment. The variance of inflation is then proportional to the variance of the first difference of employment. With at least moderate persistence, the variance of the first difference of employment is less then the variance of employment.

In addition, a price level target has the advantage of eliminating any inflation bias that results under discretion if the employment target exceeds the natural rate of employment. It is replaced by a harmless price level bias. Indeed, with at least moderate persistence, even if society prefers to minimize inflation variability rather than price level variability, it will be better off by assigning a price level target to the central bank rather than an inflation target. The variance of inflation will be lower, there is no inflation bias, and with expectations incorporating price level targeting, employment variability will be the same as under inflation targeting. ${ }^{4}$

\footnotetext{
${ }^{3}$ Svensson (1996) makes the point that infation targeting regimes should be interpreted as having explicit unemployment or output targets, and compares inflation targeting regimes to (1) Rogoff (1985) 'conservative' central banks with more weight on inflation stabilization, (2) 'linear infation contracts' proposed by Walsh (1995) and extended by Persson and Tabellini (1993), and (3) 'output targeting' regimes, both with and without persistence in output and unemployment. For instance, without persistence, an optimal inflation target equal to the socially best inflation rate less any discretionary inflation bias is identical to a linear infation contract and better than a Rogoff 'conservative' central bank.

4 The consequences of downward nominal rigidity and nonnegative nominal interest rates are discussed in the concluding section.
} 
Section 2 presents the model with inflation targeting. Section 3 introduces price level targeting. Section 4 evaluates price targeting equilibria with inflation targeting preferences. Section 5 provides conclusions. An appendix presents technical details, including some results on exogenous inflation and price level processes.

\section{Inflation targeting}

The treatment of inflation targeting under persistence follows Svensson (1996), which in turn builds on the recent extension of the analysis of rules and discretion in monetary policy to the case of persistence in Lockwood and Philippopoulos (1994), Jonsson (1995) and Lockwood, Miller and Zhang (1995). The short-run Phillips curve is

$$
l_{t}=\rho l_{t-1}+\alpha\left(\pi_{t}-\pi_{t}^{e}\right)+\epsilon_{t}
$$

where $l_{t}$ is (the log) employment rate in period $t, \alpha$ and $\rho$ are constants $(\alpha>0$ and $0 \leq \rho<1$ ), $\pi_{t}=p_{t}-p_{t-1}$ is the (log of the gross) inflation rate, $p_{t}$ is the (log) price level, $\pi_{t}^{e}$ denotes price level expectations in period $t-1$ of the price level in period $t$, and $\epsilon_{t}$ is an i.i.d. supply shock with mean 0 and variance $\sigma^{2}$. The private sector has rational expectations. That is,

$$
\pi_{t}^{e}=\mathrm{E}_{t-1} \pi_{t}
$$

where $\mathrm{E}_{t-1}$ denotes expectations conditional upon information available in period $t-1$, which includes the realization of all variables up to and including period $t-1$, as well as the constant parameters of the model. The short-run Phillips curve corresponds, for instance, to a situation in which nominal wages for period $t$ are set one period in advance, based on expectations in period $t-1$, without knowing the supply shock $\epsilon_{t}$ in period $t$. The (long-run) natural employment rate, which I identify with the unconditional mean of the employment rate, $\mathrm{E}\left[l_{t}\right]$, is for convenience set equal to zero. The autoregressive term arises, for instance, in wage setting models where trade unions set nominal wages one period in advance, disregarding non-union workers' preferences and only taking into account union members' preferences for real wages and employment, and where union membership depends on previous employment.

The social preferences are represented by the social loss function

$$
V=\mathrm{E}_{\mathbf{0}}\left[\sum_{t=1}^{\infty} \beta^{t-1} L_{t}\right]
$$


with the "period" loss function

$$
L_{t}=\frac{1}{2}\left[\left(\pi_{t}-\pi^{*}\right)^{2}+\lambda\left(l_{t}-l^{*}\right)^{2}\right]
$$

The period loss function is characterized by three parameters: $\pi^{*}$ is the socially best inflation rate, $l^{*}$ is the socially best employment rate, and $\lambda>0$ is the social weight on employment stabilization relative to inflation stabilization. The (log of the) socially best employment rate, $l^{*}$, is assumed to be at least as large as the natural employment rate, hence $l^{*} \geq 0$. Then $l^{*}$ can be interpreted as a measure of the distortion in the labor market that causes the socially best employment level to exceed the natural employment level. Alternatively, $l^{*}$ can be interpreted as a measure of the extent to which the employment target is overambitious. The role of the overambitious employment target in the analysis is to introduce a benefit from inflation surprises. As noted in the literature, such benefits can also arise for other reasons, for instance, if a surprise real depreciation of the nominal public debt is less distortionary than explicit taxation. For the purpose of this paper, it is not crucial that the employment target is above the natural rate. ${ }^{5}$

The central bank is for simplicity assumed to have perfect control over the inflation rate $\pi_{t}$. It sets the inflation rate in each period after having observed the current supply shock $\epsilon_{t}{ }^{6}$

\subsection{Commitment}

The optimal rule under commitment is derived as the solution to the problem

$$
V^{*}\left(l_{t-1}\right)=\min _{\pi_{t}, \pi_{t}^{e}} \mathrm{E}_{t-1}\left\{\frac{1}{2}\left[\left(\pi_{t}-\pi^{*}\right)^{2}+\lambda\left(l_{t}-l^{*}\right)^{2}\right]+\beta V^{*}\left(l_{t}\right)\right\}
$$

subject to (2.1) and (2.2). The lagged employment rate enters as a state variable. Here $\pi_{t}$ may depend on both the supply shock $\epsilon_{t}$ and the lagged employment rate $l_{t-1}$, whereas $\pi_{t}^{e}$ may only depend on $l_{t-1}$. The indirect loss function $V^{*}\left(l_{t-1}\right)$ will be quadratic and can be written

$$
V^{*}\left(l_{t-1}\right)=\gamma_{0}^{*}+\gamma_{1}^{*} l_{t-1}+\frac{1}{2} \gamma_{2}^{*} l_{t-1}^{2}
$$

It is shown in the appendix that the optimal rule is

$$
\pi_{t}=\pi^{*}-b^{*} \epsilon_{t}
$$

\footnotetext{
${ }^{5}$ Results for $l^{*}=0$ will be reported in footnotes.

6 The results are not affected if output is considered the control variable; or (cf. Rogoff (1985)) if an aggregate demand equation is also added where aggregate demand depends on the real interest rate and the nominal interest rate is the instrument of monetary policy; or if a money demand equation is also added and money supply is the instrument. A control error on the price level will, however, affect the results somewhat, as explained below.
} 
where

$$
b^{*}=\frac{\left(\lambda+\beta \gamma_{2}^{*}\right) \alpha}{1+\left(\lambda+\beta \gamma_{2}^{*}\right) \alpha^{2}}=\frac{\lambda \alpha}{1+\lambda \alpha^{2}-\beta \rho^{2}}
$$

and

$$
\gamma_{2}^{*}=\frac{\lambda \rho^{2}}{1-\beta \rho^{2}}
$$

The employment rate will then fulfill

$$
l_{t}=\rho l_{t-1}+\left(1-\alpha b^{*}\right) \epsilon_{t} .
$$

We see that the optimal inflation response to supply shocks is larger under persistence $(\rho>0$, $\left.\gamma_{2}^{*}>0\right)$ than without $\left(\rho=\gamma_{2}^{*}=0\right)$. Since current employment changes affect future employment, it becomes more important to stabilize employment; hence inflation is allowed to fluctuate more. Note that inflation only depends on the private information of the central bank; any dependence on information known by the private sector just goes into expected inflation, which adds to the loss function without affecting employment; cf. Persson and Tabellini (1993).

The results are summarized in Table 1 , the column for Commitment. Conditional and unconditional expected inflation equal the inflation target, rows (5) and (6). The conditional and unconditional variance of inflation are equal and given in rows (7) and (8).

The future price level is a random walk with drift,

$$
p_{T}=p_{t}+(T-t) \pi^{*}-b^{*} \sum_{\tau=t+1}^{T} \epsilon_{\tau}, \quad T>t,
$$

and its conditional variance will hence be increasing in the horizon, row (11). The unconditional variance of the price level, row (12), is hence unbounded.

Long term inflation will be

$$
\frac{p_{T}-p_{t}}{T-t}=\pi^{*}-b^{*} \frac{\sum_{\tau=t+1}^{T} \epsilon_{T}}{T-t}, \quad T>t
$$

with conditional and unconditional expectation equal to the inflation target, rows (14) and (15). The conditional variance of long term inflation will be decreasing in the horizon, row (16), and equal to the unconditional variance, row (17).

\subsection{Discretion}

Under discretion the decision problem of the central bank can be written

$$
\hat{V}\left(l_{t-1}\right)=\mathrm{E}_{t-1} \min _{\pi_{t}}\left\{\frac{1}{2}\left[\left(\pi_{t}-\pi^{*}\right)^{2}+\lambda\left(l_{t}-l^{*}\right)^{2}\right]+\beta \hat{V}\left(l_{t}\right)\right\}
$$


where the minimization in period $t$ is subject to (2.1) but is done for given inflation expectations $\pi_{t}^{e}$. The central bank thus no longer internalizes the effect of its decisions on inflation expectations, although it takes into account that changes in current employment will affect current expectations of future inflation (this is incorporated in $\hat{V}\left(l_{t}\right)$ ). The indirect loss function can be written

$$
\hat{V}\left(l_{t-1}\right)=\hat{\gamma}_{0}+\hat{\gamma}_{1} l_{t-1}+\frac{1}{2} \hat{\gamma}_{2} l_{t-1}^{2} .
$$

In the appendix it is shown that the decision rule and employment rate fulfill ${ }^{7}$

$$
\begin{gathered}
\pi_{t}=\hat{a}-\frac{\hat{b}}{1-\alpha \hat{b}} l_{t}=\hat{a}-\frac{\hat{b}}{1-\alpha \hat{b}} \rho l_{t-1}-\hat{b} \epsilon_{t}, \\
l_{t}=\rho l_{t-1}+(1-\alpha \hat{b}) \epsilon_{t} .
\end{gathered}
$$

The constants are given by

$$
\hat{a}=\pi^{*}+\lambda \alpha l^{*}-\beta \alpha \hat{\gamma}_{1}, \quad \hat{b}=\frac{\left(\lambda+\beta \hat{\gamma}_{2}\right) \alpha}{1+\left(\lambda+\beta \hat{\gamma}_{2}\right) \alpha^{2}},
$$

where

$$
\begin{gathered}
\hat{\gamma}_{1}=-\frac{\lambda l^{*}\left[1+\left(\lambda+\beta \hat{\gamma}_{2}\right) \alpha^{2}\right] \rho}{1-\beta \rho\left[1+\left(\lambda+\beta \hat{\gamma}_{2}\right) \alpha^{2}\right]} \leq 0, \\
\hat{\gamma}_{2}=\frac{1-\beta \rho^{2}-2 \lambda \beta \alpha^{2} \rho^{2}-\sqrt{\left(1-\beta \rho^{2}\right)^{2}-4 \lambda \beta \alpha^{2} \rho^{2}}}{2(\beta \alpha \rho)^{2}}>0 .
\end{gathered}
$$

As explained in the appendix an existence condition must be fulfilled. ${ }^{8}$

The results under discretion are summarized in Table 1, the column for Discretion. The decision rule can be written as a feedback rule on current employment, or as a function of lagged employment and the current supply shock. Without persistence, that is, for $\rho=0$, we have $\hat{\gamma}_{2}=\gamma_{2}^{*}=0$. Then the inflation response to supply shocks under discretion is the same as the optimal rule, $\hat{b}=b^{*}$. With persistence, we have $\hat{\gamma}_{2}>\gamma_{2}^{*}$ (see appendix), and by comparing (2.15) and (2.8) we see that, under discretion, there is a stabilization bias in that the inflation response to supply shocks is larger than the optimal rule,

$$
\hat{b}>b^{*}
$$

Since under discretion the future inflation bias depends on the current employment rate, it becomes even more important to stabilize the employment rate, which requires a stronger inflation

\footnotetext{
7 The equilibrium concept is a Markov-perfect equilibrium where trigger strategies are not allowed and actions depend on history only via the lagged state variable, $u_{t-1}$ (cf. Lockwood and Philippopoulos (1994)).

If $u^{*}=0$, the decision rule has $\hat{\gamma}_{1}=0, \hat{a}=\pi^{*}$.
} 
response. Thus, conditional and unconditional employment variability is lower under discretion than under commitment, rows (2) and (3) in Table 1.

Conditional expected inflation is given in row (5). We see that the inflation bias, $\mathrm{E}_{t} \pi_{t+1}-\pi^{*}$, depends on lagged employment and is hence state-dependent. The average inflation bias,

$$
\mathrm{E}\left[\pi_{t}\right]-\pi^{*}=\lambda \alpha l^{*}-\beta \alpha \hat{\gamma}_{1}
$$

is larger than the inflation bias $\lambda \alpha l^{*}$ without employment persistence. ${ }^{9}$

The conditional and unconditional variance of inflation is higher under discretion, rows (7) and (8), since the inflation rate is a linear function of employment rather than of the supply shock.

The future price level is an I(1) process that fulfills

$$
p_{T}=p_{t}+\sum_{\tau=t+1}^{T} \pi_{\tau}=p_{t}+(T-t) \hat{a}-\frac{\hat{b}}{1-\alpha \hat{b}} \sum_{\tau=t+1}^{T} l_{\tau},
$$

and long-term inflation will be

$$
\frac{p_{T}-p_{t}}{T-t}=\hat{a}-\frac{\hat{b}}{1-\alpha \hat{b}} \frac{\sum_{\tau=t+1}^{T} l_{\tau}}{T-t}
$$

Thus, expectations and variances of the future price level and long-term inflation in rows (14)(17) will depend on the expectations and variances of the sum and average of future employment rates. These are reported in Table 2.

\footnotetext{
${ }^{\circ}$ If $l^{*}=0$, the average inflation bias is zero.
} 
Table 1. Inflation targeting

Commitment

Discretion

$\begin{array}{cccc}(1) & l_{t} & \rho l_{t-1}+\left(1-\alpha b^{*}\right) \epsilon_{t} & \rho l_{t-1}+(1-\alpha \hat{b}) \epsilon_{t} \\ (2) & \operatorname{Var}_{t} l_{t+1} & \left(1-\alpha b^{*}\right)^{2} \sigma^{2} & (1-\alpha \hat{b})^{2} \sigma^{2} \\ (3) & \operatorname{Var}\left[l_{t}\right] & \frac{\left(1-\alpha b^{*}\right)^{2} \sigma^{2}}{1-\rho^{2}} & \frac{(1-\alpha \hat{b})^{2} \sigma^{2}}{1-\rho^{2}} \\ (4) & \pi_{t} & \pi^{*}-b^{*} \epsilon_{t} & \hat{a}-\frac{\hat{b}}{1-\alpha \hat{b}} l_{t} \\ (5) & \mathrm{E}_{t} \pi_{t+1} & \pi^{*} & \hat{a}-\frac{\hat{b}}{1-\alpha \hat{b}} \rho l_{t} \\ (6) & \mathrm{E}\left[\pi_{t}\right] & \pi^{*} & \hat{a} \\ (7) & \operatorname{Var}_{t} \pi_{t+1} & b^{* 2} \sigma^{2} & \hat{b}^{2} \sigma^{2} \\ (8) & \operatorname{Var}\left[\pi_{t}\right] & b^{* 2} \sigma^{2} & \frac{\hat{b}^{2} \sigma^{2}}{1-\rho^{2}}\end{array}$

(9) $p_{t} \quad p_{t-1}+\pi^{*}-b^{*} \epsilon_{t} \quad p_{t-1}+\hat{a}-\frac{\hat{b}}{1-\alpha \hat{b}} l_{t}$

(10) $\quad p_{T} \quad p_{t}+(T-t) \pi^{*}-b^{*} \sum_{\tau=t+1}^{T} \epsilon_{\tau} \quad p_{t}+(T-t) \hat{a}-\frac{\hat{b}}{1-\alpha \hat{b}} \sum_{\tau=t+1}^{T} l_{\tau}$

(11) $\operatorname{Var}_{t} p_{T} \quad(T-t) b^{* 2} \sigma^{2} \quad\left(\frac{\hat{b}}{1-\alpha \hat{b}}\right)^{2} \operatorname{Var}_{t} \sum_{\tau=t+1}^{T} l_{\tau}$

(12) $\operatorname{Var}\left[p_{t}\right]$

(13) $\frac{p_{T}-p_{t}}{T-t}$

$\pi^{*}-b^{*} \frac{\sum_{\tau=t+1}^{T} \epsilon_{\tau}}{T-t}$

$\hat{a}-\frac{\hat{b}}{1-\alpha \hat{b}} \frac{\sum_{\tau=t+1}^{T} l_{\tau}}{T-t}$

(14) $\quad \mathrm{E}_{t} \frac{p T-p_{t}}{T-t}$

$\pi^{*}$

$\hat{a}-\frac{\hat{b}}{1-\alpha \tilde{b}} \frac{1-\rho^{T-t}}{1-\rho} \rho \frac{l_{t}}{T-t}$

(15) $\mathrm{E}\left[\frac{p_{T}-p_{t}}{T-t}\right]$

$\pi^{*}$

(16) $\operatorname{Var}_{t} \frac{\mathrm{p} T-p_{t}}{T-t}$

$b^{* 2} \frac{\sigma^{2}}{T-t}$

(17) $\operatorname{Var}\left[\frac{\mathrm{p}_{T}-\mathrm{p}_{t}}{T-t}\right]$

$b^{* 2} \frac{\sigma^{2}}{T-t}$

$\left(\frac{\hat{b}}{1-\alpha \hat{b}}\right)^{2} \frac{\operatorname{Var}_{t} \sum_{\tau=t+1}^{T} l_{\tau}}{(T-t)^{2}}$
$\left(\frac{\hat{b}}{1-\alpha \hat{b}}\right)^{2} \frac{\operatorname{Var}\left[\sum_{\tau=t+1}^{T} l_{\tau}\right]}{(T-t)^{2}}$

Table 2. Expectation and variance of future employment under discretion

$$
\begin{aligned}
l_{T} & =\rho^{T-t} l_{t}+\sum_{\tau=t+1}^{T} \rho^{T-\tau}(1-\alpha \hat{b}) \epsilon_{\tau} \\
\sum_{\tau=t+1}^{T} l_{\tau} & =\frac{1-\rho^{T-t}}{1-\rho} \rho l_{t}+\sum_{\tau=t+1}^{T} \frac{1-\rho^{T-\tau+1}}{1-\rho}(1-\alpha \hat{b}) \epsilon_{\tau} \\
\mathrm{E}_{t} \sum_{\tau=t+1}^{T} l_{\tau} & =\frac{1-\rho^{T-t}}{1-\rho} \rho l_{t} \\
\operatorname{Var}_{t} l_{T} & =\left(1-\rho^{2(T-t)}\right) \frac{(1-\alpha \hat{b})^{2} \sigma^{2}}{1-\rho^{2}} \\
\operatorname{Var}\left[l_{t}\right] & =\frac{(1-\alpha \hat{b})^{2} \sigma^{2}}{1-\rho^{2}} \\
\operatorname{Var}_{t} \sum_{\tau=t+1}^{T} l_{\tau} & =\left[(T-t)-2 \frac{1-\rho^{T-t}}{1-\rho} \rho+\frac{1-\rho^{2(T-t)}}{1-\rho^{2}} \rho^{2}\right] \frac{1-\rho^{2}}{(1-\rho)^{2}} \operatorname{Var}\left[l_{t}\right] \\
\operatorname{Var}\left[\sum_{\tau=t+1}^{T} l_{\tau}\right] & =\left\{\left[(T-t)-2 \frac{1-\rho^{T-t}}{1-\rho} \rho+\frac{1-\rho^{2(T-t)}}{1-\rho^{2}} \rho^{2}\right] \frac{1-\rho^{2}}{(1-\rho)^{2}}+\left(\frac{1-\rho^{T-t}}{1-\rho} \rho\right)^{2}\right\} \operatorname{Var}\left[l_{t}\right] \\
l_{T}-l_{t} & =-\left(1-\rho^{T-t}\right) l_{t}+\sum_{\tau=t+1}^{T} \rho^{T-\tau}(1-\alpha \hat{b}) \epsilon_{\tau} \\
\operatorname{Var}\left[l_{t}-l_{t-1}\right] & =2(1-\rho) \operatorname{Var}\left[l_{t}\right] \\
\operatorname{Var}\left[l_{T}-l_{t}\right] & =2\left(1-\rho^{T-t}\right) \operatorname{Var}\left[l_{t}\right]
\end{aligned}
$$




\section{Price level targeting}

The Phillips curve (2.1) can be written

$$
u_{t}=\rho u_{t-1}-\alpha\left(p_{t}-p_{t}^{e}\right)+\epsilon_{t}
$$

since $\pi_{t}-\pi_{t}^{e}=p_{t}-p_{t}^{e}$, where $p_{t}^{e}$ denotes the expectations in period $t-1$ of the $(\log )$ price level in period $t$. The private sector's rational expectations imply

$$
p_{t}^{e}=\mathrm{E}_{t-1} p_{t}
$$

Under price level targeting, the period loss function is

$$
L_{t}=\frac{1}{2}\left[\left(p_{t}-p_{t}^{*}\right)^{2}+\lambda\left(l_{t}-l^{*}\right)^{2}\right]
$$

where $p_{t}^{*}$ is the socially best (log) price level. In order to be consistent with the socially best inflation rate, the socially best price level fulfills

$$
p_{t}^{*}=p_{t-1}^{*}+\pi^{*}
$$

The previous assumption that the central bank has perfect control over inflation implies that it has perfect control over the price level. It sets the price level in each period after having observed the current supply shock $\epsilon_{t}{ }^{10}$

\subsection{Commitment}

Under commitment to an optimal rule the decision problem is

$$
V^{*}\left(l_{t-1}\right)=\min _{p_{t}, p_{t}^{e}} \mathrm{E}_{t-1}\left\{\frac{1}{2}\left[\left(p_{t}-p_{t}^{*}\right)^{2}+\lambda\left(l_{t}-l^{*}\right)^{2}\right]+\beta V^{*}\left(l_{t}\right)\right\}
$$

${ }^{10}$ Nominal income targeting has been examined for instance in Bean (1983), in several contributions in Bryant, Hooper and Mann (1993), in Henderson and McKibbin (1993), in McCallum (1990), and more recently in Hall and Mankiw (1994). One has to distinguish between targeting the level and the growth rate of nominal income. Nominal income level targeting would in the present framework correspond to

$$
L_{t}^{Y}=\frac{1}{2}\left[Y_{t}-Y_{t}^{*}\right]^{2}
$$

where $Y_{t}$ and $Y_{t}^{*}$ are (the log of) nominal income and its target, $Y_{t}=p_{t}+y_{t}, Y_{t}^{*}=p_{t}^{*}+y^{*}$, and $y_{t}$ and $y^{*}$ are (the $\log$ of) real output and its target. Let for simplicity $y_{t}=l_{t}$. Then,

$$
\begin{aligned}
L_{t}^{Y}= & \frac{1}{2}\left[Y_{t}-Y_{t}^{*}\right]^{2}=\frac{1}{2}\left[\left(p_{t}-p_{t}^{*}\right)^{2}+\left(l_{t}-l^{*}\right)^{2}\right] \\
& +\left(p_{t}-p^{*}\right)\left(l_{t}-l^{*}\right) .
\end{aligned}
$$

Thus, nominal income targeting is not exactly equal to price level targeting with $\lambda=1$; the cross term enters as well. The difference is, of course, that nominal income level targeting implies a constant unitary marginal rate of substitution between the price level and the employment rate, regardless of the levels of these variables. 
subject to (3.1) and (3.2). The price level $p_{t}$ may depend on the lagged employment rate and the current supply shock; expectations $p_{t}^{e}$ depend on the lagged employment rate only.

The decision problem is identical to that of an inflation target under commitment, (2.5), except that $p_{t}$ and $p_{t}^{*}$ replace $\pi_{t}$ and $\pi^{*}$. Thus the indirect loss function is unchanged. With the same reasoning as above, the optimal decision rule is

$$
p_{t}=p_{t}^{*}-b^{*} \epsilon_{t}
$$

with $b^{*}$ given by (2.8). The employment rate will then fulfill (2.10).

The result is summarized in Table 3, the column for Commitment. The future price level is no longer a random walk with drift but trend-stationary and given by

$$
p_{T}=p_{T}^{*}-b^{*} \epsilon_{T}=p_{t}+(T-t) \pi^{*}-b^{*}\left(\epsilon_{T}-\epsilon_{t}\right),
$$

with conditional and unconditional expectation equal to $p_{T}^{*}=p_{t}^{*}+(T-t) \pi^{*}$, and constant conditional and unconditional variance, row (11) and (12).

Inflation fulfills

$$
\pi_{t}=p_{t}-p_{t-1}=\pi^{*}-b^{*}\left(\epsilon_{t}-\epsilon_{t-1}\right)
$$

The condition expected inflation is no longer constant, row (5). The unconditional variance of inflation is twice the conditional variance, row (7) and (8).

Long-term inflation is given by

$$
\frac{p_{T}-p_{t}}{T-t}=\pi^{*}-b^{*} \frac{\epsilon_{T}-\epsilon_{t}}{T-t}
$$

The conditional expectation of the long-term inflation rate is given in row (14). The conditional and unconditional variance is decreasing by the square of the horizon, row (16) and (17).

\subsection{Discretion}

Under discretion, the decision problem of the central bank can be written

$$
\hat{V}\left(l_{t-1}\right)=\mathrm{E}_{t-1} \min _{p_{t}}\left\{\frac{1}{2}\left[\left(p_{t}-p_{t}^{*}\right)^{2}+\lambda\left(l_{t}-l^{*}\right)^{2}\right]+\beta \hat{V}\left(l_{t}\right)\right\}
$$

where the minimization in period $t$ is subject to (2.1) but is done for given price level expectations $p_{t}^{e}$. Thus the central bank no longer internalizes the effect of its decisions on price level expectations, although it takes into account that changes in current employment will affect current expectations of future price levels (this is incorporated in $\hat{V}\left(l_{t}\right)$ ). 
Except for the change in variables from $\pi_{t}$ to $p_{t}$, the decision problem is the same as under inflation targeting. Thus, the indirect loss function will be the same as under inflation targeting. By the same argument as above the decision rule fulfills

$$
p_{t}=\hat{a}_{t}-\frac{\hat{b}}{1-\alpha \hat{b}} l_{t}=\hat{a}_{t}-\frac{\hat{b}}{1-\alpha \hat{b}} \rho l_{t-1}-\hat{b} \epsilon_{t}
$$

with

$$
\hat{a}_{t}=p_{t}^{*}+\lambda \alpha l^{*}-\beta \alpha \hat{\gamma}_{1}
$$

where $\hat{b}$ is given by (2.15), $\hat{\gamma}_{1}$ and $\hat{\gamma}_{2}$ are given by (2.16) and (2.17), and the same existence condition is fulfilled. The employment rate will behave as (2.14).

With persistence, the price level response to supply shocks is larger under discretion than under commitment. Since, under discretion, the future price level bias depends on current employment, it becomes even more important to stabilize employment. This requires a stronger price level response. The price level under price level targeting behaves precisely as the inflation rate under inflation targeting, with an average and state-contingent price level bias instead of an inflation bias.

The results are summarized in Table 3, the column for Discretion. The future price level is

$$
p_{T}=\hat{a}_{T}-\frac{\hat{b}}{1-\alpha \hat{b}} l_{T}
$$

and depends only on future employment. The conditional and unconditional variance are reported in row (11) and (12).

Inflation will be given by

$$
\pi_{t}=p_{t}-p_{t-1}=\pi^{*}-\frac{\hat{b}}{1-\alpha \hat{b}}\left(l_{t}-l_{t-1}\right),
$$

where I have used (3.4). We see that there is no average inflation bias under price level targeting, row (6), although there is a state-contingent inflation bias, row (5). The conditional variance of inflation is the same as under inflation targeting, row (7), whereas the unconditional variance is different, row (8).

Indeed, comparing inflation under inflation targeting and price level targeting, we note that inflation under inflation targeting is a linear function of employment (Table 1, row (4)), whereas under price level targeting it is a linear function of the first difference of employment (Table 2, row (4)). The unconditional variance of these are by Table 2 related as

$$
\operatorname{Var}\left[l_{t}-l_{t-1}\right]=2(1-\rho) \operatorname{Var}\left[l_{t}\right]
$$


Since the unconditional variance of the first difference of the employment rate is lower than the unconditional variance of output if $\rho>\frac{1}{2}$, it follows that the unconditional variance of inflation is lower under price level targeting if the employment rate is at least moderately persistent. If $l^{*}=0, \rho>\frac{1}{2}$ is both necessary and sufficient for a lower variance of inflation under price level targeting; if $l^{*}>0, \rho>\frac{1}{2}$ is sufficient but not necessary.

Long-term inflation is

$$
\frac{p_{T}-p_{t}}{T-t}=\pi^{*}-\frac{\hat{b}}{1-\alpha \hat{b}} \frac{l_{T}-l_{t}}{T-t}
$$

and depends on the average difference between future and current employment, $\frac{l_{T}-l_{t}}{T-t}$, whereas under inflation targeting it depends on the average sum of future employment, $\frac{\sum_{\tau=t+1}^{T} l_{\tau}}{T-t}$. The conditional and unconditional variances are reported in Table 3, rows (16) and (17), cf. Table 2.

Table 3. Price level targeting

$$
\text { Commitment Discretion }
$$

(11) $\quad \operatorname{Var}_{t} p_{T}$

(12) $\operatorname{Var}\left[p_{t}\right]$

(13) $\frac{p_{T}-p_{t}}{T-t}$

(15) $\mathrm{E}\left[\frac{p_{T}-p_{t}}{T-t}\right]$

(16) $\operatorname{Var}_{t} \frac{p_{T}-p_{t}}{T-t}$

(17) $\operatorname{Var}\left[\frac{p_{T}-p_{1}}{T-t}\right]$

$$
\begin{array}{cc}
\rho l_{t-1}+\left(1-\alpha b^{*}\right) \epsilon_{t} & \rho l_{t-1}+(1-\alpha \hat{b}) \epsilon_{t} \\
\left(1-\alpha b^{*}\right)^{2} \sigma^{2} & (1-\alpha \hat{b})^{2} \sigma^{2} \\
\frac{\left(1-\alpha b^{*}\right)^{2} \sigma^{2}}{1-\rho^{2}} & \frac{(1-\alpha \hat{b})^{2} \sigma^{2}}{1-\rho^{2}} \\
\pi^{*}-b^{*}\left(\epsilon_{t}-\epsilon_{t-1}\right) & \pi^{*}-\frac{\hat{b}}{1-\alpha \hat{b}}\left(l_{t}-l_{t-1}\right) \\
\pi^{*}+b^{*} \epsilon_{t} & \pi^{*}+\frac{\hat{b}}{1-\alpha \hat{b}}(1-\rho) l_{t} \\
\pi^{*} & \pi^{*} \\
b^{* 2} \sigma^{2} & \frac{\hat{b}^{2} \sigma^{2}}{1+\rho} \\
2 b^{* 2} \sigma^{2} & \hat{a}_{t}-\frac{\hat{b}}{1-\alpha \hat{b}} l_{t} \\
p_{t}^{*}-b^{*} \epsilon_{t} & \hat{a}_{T}-\frac{\hat{b}}{1-\alpha \hat{b}} l_{T} \\
p_{T}^{*}-b^{*} \epsilon_{T} & \frac{1-\rho^{2(T-t)}}{1-\rho^{2}} \hat{b}^{2} \sigma^{2} \\
b^{* 2} \sigma^{2} & \frac{\hat{b}^{2} \sigma^{2}}{1-\rho^{2}} \\
b^{* 2} \sigma^{2} & \pi^{*}-\frac{\hat{b}}{1-\alpha \hat{b}} \frac{l_{T}-l_{t}}{T-t} \\
\pi^{*}-b^{*} \frac{\epsilon_{T}-\epsilon_{t}}{T-t} & \pi^{*}+\frac{\hat{b}}{1-\alpha \hat{b}} \frac{\left(1-\rho^{T-t}\right) l_{t}}{T-t} \\
\pi^{*}+b^{*} \frac{\epsilon_{t}}{T-t} & \pi^{*} \\
\pi^{*} & \left(\frac{\hat{b}}{1-\alpha \hat{b}}\right)^{2} \frac{V_{B r} l_{T}}{(T-t)^{2}} \\
b^{* 2} \frac{\sigma^{2}}{(T-t)^{2}} & \left(\frac{\hat{b}}{1-\alpha \hat{b}}\right)^{2} \frac{V_{a r}\left(l_{T}-l_{t}\right]}{(T-t))^{2}} \\
2 b^{* 2} \frac{\sigma^{2}}{(T-t)^{2}} &
\end{array}
$$




\section{Evaluation of price level target equilibria with inflation target preferences}

If social preferences correspond to the price level period loss function (3.3), it is obvious that a price level target equilibrium is preferable to an inflation target equilibrium. The two equilibria have identical employment behavior, but in the inflation target equilibrium the price level is non-trend-stationary and furthermore grows faster than the target price level by the inflation bias.

If social preferences correspond to the inflation target period loss function (2.4), can the price level target equilibrium still be preferable? That is, would it be preferable to assign a price level target to the central bank even if social preferences concern inflation rather than the price level. In order to answer this question, both equilibria must be evaluated with the inflation-target social loss function. For the inflation target equilibrium, the relevant indirect loss function is defined in the decision problem (2.11) and given by (2.12), with the coefficients $\hat{\gamma}_{1}$ and $\hat{\gamma}_{2}$ given by (2.16) and (2.17). The coefficient $\hat{\gamma}_{0}$ is derived in the appendix and given in (A.16).

The value of the inflation-target social loss function for the price level target equilibrium, denoted by $V^{p}\left(l_{t-1}\right)$, is defined as

$$
V^{p}\left(l_{t-1}\right)=\mathrm{E}_{t-1}\left\{\frac{1}{2}\left[\left(\pi_{t}-\pi^{*}\right)^{2}+\lambda\left(l_{t}-l^{*}\right)^{2}\right]+\beta V^{p}\left(l_{t}\right)\right\}
$$

where (3.10) and (2.14) is substituted for $\pi_{t}$ and $l_{t}$. This value function will be quadratic and can be written

$$
V^{p}\left(l_{t-1}\right)=\gamma_{0}^{p}+\gamma_{1}^{p} l_{t-1}+\frac{1}{2} \gamma_{2}^{p} l_{t-1}^{2}
$$

where the coefficients $\gamma_{0}^{p}, \gamma_{1}^{p}$ and $\gamma_{2}^{p}$ remain to be determined.

In order to answer the question above, I thus need to compute

$$
V^{p}\left(l_{t-1}\right)-\hat{V}\left(l_{t-1}\right)=\left(\gamma_{0}^{p}-\hat{\gamma}_{0}\right)+\left(\gamma_{1}^{p}-\hat{\gamma}_{1}\right) l_{t-1}+\frac{1}{2}\left(\gamma_{2}^{p}-\hat{\gamma}_{2}\right) l_{t-1}^{2}
$$

This is done in detail in the appendix. However, it is intuitively clear that price level targeting is better than inflation targeting if society has inflation target preferences (if there is at least moderate employment persistence), since with price level targeting (i) the variability of inflation is less, (ii) any inflation bias is eliminated, and (iii) employment behavior is the same.

This result can be further illuminated by a direct comparison of the decision rules. The optimal rule under commitment with inflation targeting is (2.7). Due to (2.10), it can be written

$$
\pi_{t}=\pi^{*}-\frac{b^{*}}{1-\alpha b^{*}}\left(l_{t}-\rho l_{t-1}\right)
$$


Inflation targeting under discretion delivers the decision rule

$$
\pi_{t}=\hat{a}-\frac{\hat{b}}{1-\alpha \hat{b}} l_{t},
$$

where $\hat{a} \geq \pi^{*}$ and $\hat{b}>b^{*}$. Price level targeting under discretion delivers the decision rule

$$
\pi_{t}=\pi^{*}-\frac{\hat{b}}{1-\alpha \hat{b}}\left(l_{t}-l_{t-1}\right) .
$$

Clearly, under discretion, price level targeting may deliver a better approximation to the optimal

rule (4.4) than inflation targeting: The coefficient $\frac{\hat{b}}{1-\alpha \hat{b}}$ is the same under both kinds of targeting (although larger than under commitment). Unemployment behavior is the same. There is no average inflation bias under price level targeting, and, with enough persistence, the first difference of the employment rate, $l_{t}-l_{t-1}$, is a better approximation to the unanticipated change in the employment rate, $l_{t}-\rho l_{t-1}$, than just the employment rate, $l_{t}$.

This comparison of decision rules also reveals that price level targeting under discretion does not deliver the optimal rule for inflation targeting under commitment. Svensson (1996) examines how modified inflation targets can improve the discretionary equilibrium with persistence in employment and compares with Rogoff (1985) 'conservative' central banks and with Walsh (1995)-Persson and Tabellini (1993) linear inflation contracts.

\section{Conclusions}

According to an emerging, although not completely unanimous (cf. Dillon and Fellow (1994)) conventional wisdom, the choice between price level targeting and inflation targeting involves a trade-off between (1) less low-frequency price level variability and (2) less high-frequency inflation and employment variability. This conventional wisdom arises from the use of exogenous reaction functions or exogenous inflation and price level processes, which may or may not be consistent with objectives and constraints (including commitment technologies) faced by central banks. In contrast, this paper examines price level and inflation targeting by deriving endogenous decision rules and equilibrium price level and inflation processes, when central banks have been assigned price level or inflation targets and, realistically, act under discretion and face persistent employment.

In this framework, price level targeting naturally results in lower low-frequency price level variability than inflation targeting. However, if employment persistence is at least moderate, it also results in lower high-frequency inflation variability, counter to conventional wisdom. The 
reason is that under inflation targeting inflation depends on the employment rate, whereas under price level targeting it depends on the change in the employment rate; with sufficient persistence, the change in the rate is less variable than the rate itself.

In addition, price level targeting eliminates the average inflation bias that results under inflation targeting when the implicit employment target is lower than the natural employment rate.

If society's preferences correspond to price level targeting, price level targeting is clearly better than inflation targeting, since the latter results in a non-trend-stationary price level and, when there is an inflation bias, in a price level that increasingly deviates from the target price level. If society's preferences instead correspond to inflation targeting, because of the reduced inflation variability and inflation bias, it is still better for society to assign a price level target to the central bank (if employment persistence is at least moderate). This result can also be understood with reference to the optimal rule under commitment. Under commitment and inflation targeting, inflation depends only on the private information of the central bank, in this case the supply shock. Under discretion and inflation targeting, inflation depends on the employment rate; under price level targeting inflation depends on the change in the employment rate; when employment is persistent, the latter is a better approximation to the supply shock than the former .

The paper has demonstrated the importance of employment persistence for the results, and, I hope, the benefits of deriving endogenous decision rules for assigned targets rather than using postulated reaction functions.

In the model used here price level targeting and inflation targeting result in the same employment variability. This is because both regimes result in the same conditional one-period variance of the price level and the inflation rate (although the unconditional variability of one-period inflation, and the conditional more-than-one-period variance of the price level and inflation rate, are lower under price level targeting), and only the unanticipated part of one-period price movements affect employment.

However, if nominal wages are downwardly rigid, anticipated negative inflation (deflation) would increase real wages and increase employment. This may increase employment variability; in particular it may reduce average employment. The effect has been studied by Lebow, Roberts and Stockton (1992), Crawford and Dupasquier (1994), Fillon and Tetlow (1994) and Akerlof, Dickens and Perry (1996). For given inflation variability, the effect depends on the average 
inflation rate, regardless of whether there is price level or inflation targeting. The effect is hence an argument for a positive inflation target under inflation targeting and a price level target that increases at a steady rate during price level targeting, since that would reduce the frequency of deflation. However, the reduced variability of inflation under price level targeting still seems to be an argument in favor of price level targeting. Productivity growth will in any case reduce the effect. For the United States, Lebow Stockton and Wascher (1995) report empirical evidence that indicate little downward rigidity and very small aggregate output effects of reducing U.S. inflation to zero, and in simulations Fillon and Tetlow (1994) also report small output effects. Akerlof, Dickens and Perry (1996) find larger output and unemployment effects, though. Any degree of downward nominal rigidity is, however, likely to be endogenous and regime dependent and hence decrease with less inflation. ${ }^{11}$

Nonnegative nominal interest rates have also been used as an argument for a positive inflation rate, since low or negative inflation could then result in too high real interest rates, and in particular prevent monetary policy from being sufficiently expansionary in recessions (Summers (1991)). But, Lebow (1993) shows that monetary policy can still be expansionary by using other instruments than interest rates on government bonds and bills, if these interest rates occasionally fall to zero. In simulations Fuhrer and Madigan (1994) find very small effects on output from nonnegative nominal interest rates. The problem will be smaller, if future real interest rates are generally higher than in the $1960 \mathrm{~s}$ and the $1970 \mathrm{~s}$. For a given average inflation rate, the reduced inflation variability under price level targeting again seems to speak in favor of price level targeting.

In any case, to the extent that downwardly rigid nominal wages and nonnegative nominal interest rates imply a positive average inflation rate, there is no principle difficulty with a price level target which increases at a steady rate, since that does not reduce the predictability of the price level.

The parameters of the Phillips curve (the slope, the degree of persistence, and the variance of supply shocks) might not be invariant to a shift from inflation targeting to price level targeting. It is not obvious, though, whether the parameters are likely to change and if so, in what direction, especially since conditional variances (and average inflation in case the employment target equals the natural rate) are the same in the two regimes. Clearly a more elaborate analysis with explicit microfoundations of the Phillips curve, is then required.

\footnotetext{
11 For instance, an increasingly common way to circumvent downward nominal wage rigidity in my home country is to add a flexible (and, on average positive) non-negative bonus, to a downwardly rigid wage.
} 
Will random walk measurement errors of the price level provide an argument against price level targeting? No, for if there are such measurement errors, there will be an unavoidable random walk component to the 'true' price level, but inflation targeting will add another random walk component, making the variance of the price level still higher under inflation targeting than under price level targeting.

What is the effect of control errors? Suppose there are i.i.d. control errors, $\eta_{t}$, on the price level, with variance $\sigma_{\eta}^{2}$. Under inflation targeting, this will add $\sigma_{\eta}^{2}$ to the variance of inflation. Under price level targeting, this will be added twice to the variance of inflation, which means that the degree of persistence must be somewhat higher (than a half), in order to make the inflation variance less under price level targeting (unless the variance due to control errors is so large as to dominate all other sources of variability).

Do social preferences correspond to inflation targeting or price level targeting? What are the social benefits of reduced long-term uncertainty of the price level? This seems to be an underresearched area (see Konieczny (1994) and Duguay (1994) for discussion). There are obvious informational and computational benefits of a stable, or at least predictable, unit of account for intertemporal decisions and for decisions that occur relatively infrequently. Although these benefits are obvious, they are difficult to asses quantitatively. Standard economic theory is certainly at a disadvantage assessing such costs, since it relies on the assumption on unbounded computational capacity of agents. I believe that we have to some extent become so used to a randomly increasing price level that we have grown blind to the information and computation costs it imposes. It has been argued that the analogy to length and other physical units is revealing: Suppose that the meter or the foot were to be randomly reduced each year. We could certainly live in such a world; we would only have to keep track of which year meter or foot things were measured in, and we could carry a card in our wallets with the appropriate conversion factors. We could certainly live in such a world; but it would no doubt be a considerable struggle. For some reason, we have come to accept such a state of affairs in the economic sphere.

Reduced long-term uncertainty would obviously reduce the uncertainty associated with longterm nominal contracts, like long-term nominal bonds. But if the cost of such uncertainty is significant, why is it not circumvented by indexation? One possibility is that the information and computational cost of indexation is itself substantial; the fact that citizens seem to shift to foreign currency as a unit of account only when domestic inflation goes above 20-30 percent per year has been quoted as evidence that those costs may be quite substantial (Konieczny (1994)). 
More work on formal models of the costs of long-term price level uncertainty would be very welcome.

As noted by Konieczny (1994), these ideas were well put a long time ago:

If there is anything in the world which ought to be stable it is money, the measure of everything which enters the channels of trade. What confusion would there not be in a state where weights and measures frequently changed? On what basis and with what assurance would one person deal with another, and which nations would come to deal with people who lived in such disorder? (François Le Blanc (1690), Traité Historique de Monnayes de France, Paris, quoted by Einaudi (1953, p. 233).)

\section{Appendix}

\section{A Inflation targeting}

\section{A.1 Commitment to an optimal rule}

The first order conditions with respect to $\pi_{t}$ and $\pi_{t}^{e}$ result in

$$
\left(\pi_{t}-\pi^{*}\right)+\lambda \alpha\left(l_{t}-l^{*}\right)+\beta \alpha V_{l}^{*}\left(l_{t}\right)-\mathrm{E}_{t-1}\left[\lambda \alpha\left(l_{t}-l^{*}\right)+\beta \alpha V_{l}^{*}\left(l_{t}\right)\right]=0,
$$

where the Lagrange multiplier of (2.2) has been eliminated.

Taking expectations at $t-1$ of (A.1) gives

$$
\mathrm{E}_{t-1} \pi_{t}=\pi^{*}
$$

the expected inflation rate equals the socially best inflation rate and is independent of the employment rate. Substitution of (2.1), (2.2), (A.2) and (2.6) into (A.1) results in the decision rule

$$
\pi_{t}=\pi^{*}-b^{*} \epsilon_{t}
$$

with

$$
b^{*}=\frac{\left(\lambda+\beta \gamma_{2}^{*}\right) \alpha}{1+\left(\lambda+\beta \gamma_{2}^{*}\right) \alpha^{2}} .
$$

The employment rate will then fulfill

$$
l_{t}=\rho l_{t-1}+\left(1-\alpha b^{*}\right) \epsilon_{t} .
$$

In order to find $b^{*}, \gamma_{2}^{*}$ has to be determined. The coefficients $\gamma_{1}^{*}$ and $\gamma_{2}^{*}$ can be identified by substituting (A.3) and (A.5) into (2.5). Together with (2.6) this results in

$$
\gamma_{1}^{*}=-\frac{\lambda l^{*} \rho}{1-\beta \rho} \leq 0 \quad \text { and } \quad \gamma_{2}^{*}=\frac{\lambda \rho^{2}}{1-\beta \rho^{2}}>0
$$


Using this in (A.4) results in

$$
b^{*}=\frac{\lambda \alpha}{1+\lambda \alpha^{2}-\beta \rho^{2}}
$$

\section{A.2 Discretion}

The first order condition will be

$$
\pi_{t}-\pi^{*}+\lambda \alpha\left(l_{t}-l^{*}\right)+\beta \alpha \hat{V}_{l}\left(l_{t}\right)=\pi_{t}-\pi^{*}+\left(\lambda+\beta \hat{\gamma}_{2}\right) \alpha l_{t}-\left(\lambda l^{*}-\beta \hat{\gamma}_{1}\right) \alpha=0,
$$

where I have used (2.12). The marginal loss of increased inflation expectations have vanished from the first order condition.

Taking expectations of (A.8) gives

$$
\mathrm{E}_{t-1} \pi_{t}=\pi^{*}+\left(\lambda l^{*}-\beta \hat{\gamma}_{1}\right) \alpha-\left(\lambda+\beta \hat{\gamma}_{2}\right) \alpha \rho l_{t-1}
$$

Combining (2.1), (2.2), (A.8) and (A.9) gives a feedback rule of the form

$$
\pi_{t}=\hat{a}-\frac{\hat{b}}{1-\alpha \hat{b}} l_{t}
$$

with

$$
\hat{a}=\pi^{*}+\left(\lambda l^{*}-\beta \hat{\gamma}_{1}\right) \alpha \quad \text { and } \quad \hat{b}=\frac{\left(\lambda+\beta \hat{\gamma}_{2}\right) \alpha}{1+\left(\lambda+\beta \hat{\gamma}_{2}\right) \alpha^{2}}
$$

Unemployment will be given by (2.14).

In order to determine $\hat{\gamma}_{1}$ and $\hat{\gamma}_{2}$, I substitute (A.10) and (2.14) into (2.11). Using (2.12) to identify the coefficient for $l_{t-1}^{2}$ results in

$$
\hat{\gamma}_{2}=\left(\lambda+\beta \hat{\gamma}_{2}\right) \rho^{2}+\left(\lambda+\beta \hat{\gamma}_{2}\right)^{2} \alpha^{2} \rho^{2}
$$

This is a second-degree equation in $\hat{\gamma}_{2}$, which hence has two potential roots. The equation has real roots if and only if the first existence condition

$$
\lambda \leq \lambda_{1} \equiv \frac{\left(1-\beta \rho^{2}\right)^{2}}{4 \beta \alpha^{2} \rho^{2}}
$$

holds. Only the smaller solution, (2.17), is relevant (see Lockwood \& Philippopoulos (1994) and Svensson (1996)).

If the second term on the right-hand side of (A.12) were zero, $\hat{\gamma}_{2}$ would equal $\gamma_{2}^{*}$, cf. (2.9). Since the term is positive, $\hat{\gamma}_{2}>\gamma_{2}^{*}$.

Identification of the coefficient for $l_{t-1}, \hat{\gamma}_{1}$, results in (2.16). In order to ensure that there is a finite solution to $\hat{\gamma}_{1}$, the second existence condition

$$
\beta \rho\left[1+\left(\lambda+\beta \hat{\gamma}_{2}\right) \alpha^{2}\right]<1
$$


must hold. The condition has a natural interpretation: The expression on the left hand side of the inequality is the discounted total increase in the employment rate in period $t$ of a unit increase in the employment rate in period $t-1$, when inflation in period $t$ is held constant. The total effect consists of the direct effect, $\rho$, and the indirect effect via reduced inflation expectations, $\frac{\partial l_{t}}{\partial \pi_{t}^{c}} \frac{\partial \pi_{t}^{e}}{\partial l_{t-1}}$, cf. (A.9). If this discounted effect is above unity, the present value of the effect in all future periods will be unbounded.

With (2.17) one can show that (A.14) is equivalent to

$$
\lambda<\lambda_{2} \equiv \frac{(1-\beta \rho)(1-\rho)}{\beta \alpha^{2} \rho} .
$$

It is shown in Svensson (1996) that for some parameter values (A.15) is more binding than (A.13). More precisely, the complete existence condition is (i) for $\frac{1}{2}<\rho<1$ and $0<\beta<\frac{2 \rho-1}{\rho^{2}}$, $\lambda \leq \lambda_{1}$, (ii) for $\frac{1}{2} \leq \rho<1$ and $\beta=\frac{2 \rho-1}{\rho^{2}}, \lambda<\lambda_{1}=\lambda_{2}$, and (iii) for $0<\rho<1$ and $\frac{2 \rho-1}{\rho^{2}}<\beta<1$, $\lambda<\lambda_{2}<\lambda_{1}$. If $l^{*}=0$, only (A.13) is relevant. ${ }^{12}$

Identification of $\hat{\gamma}_{0}$ results in

$$
\hat{\gamma}_{0}=\frac{1}{1-\beta} \frac{1}{2}\left\{\left(\hat{a}-\pi^{*}\right)^{2}+\lambda l^{* 2}+\left[\hat{b}^{2}+\left(\lambda+\beta \hat{\gamma}_{2}\right)(1-\alpha \hat{b})^{2}\right] \sigma^{2}\right\}
$$

\section{B Evaluation of price level targeting equilibria with inflation targeting pref- erences}

Let me start with the first term on the right-hand side of (4.3). Identification of the constant $\gamma_{0}^{p}$ in (4.1) and (4.2) results, after some algebra, in

$$
\gamma_{0}^{p}=\frac{1}{1-\beta} \frac{1}{2}\left\{\lambda l^{* 2}+\left[\hat{b}^{2}+\left(\lambda+\beta \gamma_{2}^{p}\right)(1-\alpha \hat{b})^{2}\right] \sigma^{2}\right\}
$$

From (A.16) we have

$$
\hat{\gamma}_{0}=\frac{1}{1-\beta} \frac{1}{2}\left\{\left(\hat{a}-\pi^{*}\right)^{2}+\lambda l^{* 2}+\left[\hat{b}^{2}+\left(\lambda+\beta \hat{\gamma}_{2}\right)(1-\alpha \hat{b})^{2}\right] \sigma^{2}\right\}
$$

Thus

$$
\gamma_{0}^{p}-\hat{\gamma}_{0}=\frac{1}{1-\beta} \frac{1}{2}\left\{-\left(\hat{a}-\pi^{*}\right)^{2}+\beta\left(\gamma_{2}^{p}-\hat{\gamma}_{2}\right)(1-\alpha \hat{b})^{2} \sigma^{2}\right\}
$$

\footnotetext{
12 The conditions (A.14) and (A.15) do not appear in the analysis of Lockwood and Philippopoulos (1994), since they assume that $l^{*}=0$.

If $\alpha$ in (2.1) equals unity (as in Lockwood and Philippopoulos (1994) and in Lockwood, Miller and Zhang (1995)), the existence conditions appear rather restrictive. If $\beta=0.95$ and $\rho=0.4(0.8)$, we have $\frac{2 \rho-1}{\rho^{2}}=-1.25$ (0.4), so (A.15) applies. Then $\lambda_{2}=0.98(0.06)$, respectively. If $\alpha$ instead equals 0.2 , the corresponding $\lambda_{2}$ values are 25 times larger, that is, 24.5 (1.58). The corresponding values for $\lambda_{1}$ are $1.18(0.06)$ for $\alpha=1$, and 29.6 (1.58) for $\alpha=0.2$.
} 
The first term on the right-hand side is negative and obviously arises because the price level target equilibrium has no average inflation bias. The second term depends on the difference between the coefficients $\gamma_{2}^{p}$ and $\hat{\gamma}_{2}$, that is, the convexity of the indirect loss function. Identification of $\gamma_{2}^{p}$ in (4.1) and (4.2) gives

$$
\gamma_{2}^{p}=\frac{\lambda \rho^{2}+\left(\frac{\hat{b}}{1-\alpha \hat{b}}\right)^{2}(1-\rho)^{2}}{1-\beta \rho^{2}} .
$$

In order to facilitate comparison, by (A.11) and (A.12), $\hat{\gamma}_{2}$ can be written as ${ }^{13}$

$$
\hat{\gamma}_{2}=\frac{\lambda \rho^{2}+\left(\frac{\hat{b}}{1-\alpha \hat{b}}\right)^{2} \rho^{2}}{1-\beta \rho^{2}} \text {. }
$$

Hence,

$$
\gamma_{2}^{p}-\hat{\gamma}_{2}=\frac{\left(\frac{\hat{b}}{1-\alpha \hat{b}}\right)^{2}\left[(1-\rho)^{2}-\rho^{2}\right]}{1-\beta \rho^{2}}=\frac{\left(\frac{\hat{b}}{1-\alpha \hat{b}}\right)^{2}(1-2 \rho)}{1-\beta \rho^{2}} .
$$

The difference between $\gamma_{2}^{p}$ and $\hat{\gamma}_{2}$ is negative when $\rho>\frac{1}{2}$, since the inflation rate is less sensitive to lagged employment under price level targeting if $\rho>\frac{1}{2}$. A given level of $l_{t-1}$ in period $t-1$ will give rise to a squared inflation term in period $t$ equal to $\left(\frac{\hat{b}}{1-\alpha b}\right)^{2}(1-\rho)^{2} l_{t-1}^{2}$ under a price level target and equal to $\left(\frac{\hat{b}}{1-\alpha \hat{b}}\right)^{2} \rho^{2} l_{t-1}$ under an inflation target (the present value of a future sequence of such terms requires discounting by $\beta \rho^{2}$ ).

Finally, let me look at the second term in (4.3), corresponding to the linear term in the value functions. Identifying the linear term in (4.1) and (4.2) gives

$$
\gamma_{1}^{p}=-\frac{\lambda l^{*} \rho}{1-\beta \rho}
$$

In order to facilitate comparison, I use (A.11), (A.11) and (2.16) with some algebra to rewrite $\hat{\gamma}_{1}$ in terms of the average inflation bias, ${ }^{14}$

$$
\hat{\gamma}_{1}=-\frac{\lambda l^{*} \rho+\left(\hat{a}-\pi^{*}\right) \frac{\hat{b}}{1-\alpha \hat{b}} \rho}{1-\beta \rho}
$$

Hence

$$
\gamma_{1}^{p}-\hat{\gamma}_{1}=\frac{\left(\hat{a}-\pi^{*}\right) \frac{\hat{b}}{1-\alpha \hat{b}} \rho}{1-\beta \rho} \geq 0 .
$$

${ }^{13}$ Note that by $(A .11)\left(\lambda+\beta \bar{\gamma}_{2}\right) \alpha=\frac{\hat{b}}{1-a b}$. Substitute this into the second term on the right-hand side of (A.12). ${ }^{14}$ Write (2.16) as

$$
\hat{\gamma}_{1}=-\frac{\lambda \nu^{*} \rho+\lambda \alpha l^{*} c}{1-\beta \rho-\beta \alpha c}
$$

where $c=\left(\lambda+\beta \hat{\gamma}_{2}\right) \alpha \rho=\frac{b}{1-\alpha b} \rho$. Rewrite this as

$$
\hat{\gamma}_{1}=-\frac{\lambda l^{*} \rho+\left(\lambda \alpha l^{*}-\beta \alpha \hat{\gamma}_{1}\right) c}{1-\beta \rho}
$$

and use (A.11). 
This difference arises since an increase in $l_{t-1}$ reduces the loss function more under inflation targeting: the resulting reduction in $\pi_{t}$ is more beneficial since the average inflation bias is positive under inflation targeting.

The unconditional mean of $(4.3)$ is

$$
\mathrm{E}\left[V^{p}\left(l_{t-1}\right)-\hat{V}\left(l_{t-1}\right)\right]=\gamma_{0}^{p}-\hat{\gamma}_{0}+\frac{1}{2}\left(\gamma_{2}^{p}-\hat{\gamma}_{2}\right) \operatorname{Var}\left[l_{t-1}\right]
$$

This is strictly negative for $\rho>\frac{1}{2}$.

\section{Simple inflation targeting and price level targeting processes}

Suppose inflation targeting results in the AR(1) process for inflation

$$
\pi_{t}=h \pi_{t-1}+\eta_{t}
$$

where $|h|<1$ and $\eta_{t}$ is i.i.d. with $\mathrm{E}\left[\eta_{t}\right]=0$ and $\operatorname{Var}\left[\eta_{t}\right]=s^{2}$. The unconditional variance of inflation under inflation targeting, denoted $\operatorname{Var}\left[\pi_{t}\right]_{\pi}$, fulfills

$$
\operatorname{Var}\left[\pi_{t}\right]_{\pi}=\frac{s^{2}}{1-h^{2}}
$$

The price level has a unit root,

$$
p_{t}=p_{t-1}+\pi_{t}
$$

and its unconditional variance is unbounded.

Suppose price level targeting results in the AR(1) process for the price level

$$
p_{t}=k p_{t-1}+\eta_{t}
$$

where $|k|<1$. The unconditional variance of the price level, denoted $\operatorname{Var}\left[p_{t}\right]_{p}$, is then

$$
\operatorname{Var}\left[p_{t}\right]_{p}=\frac{s^{2}}{1-k^{2}}
$$

The corresponding inflation process is

$$
\pi_{t}=p_{t}-p_{t-1}=-(1-k) p_{t-1}+\eta_{t}
$$

The unconditional variance of inflation under price level targeting, $\operatorname{Var}\left[\pi_{t}\right]_{p}$, is

$$
\operatorname{Var}\left[\pi_{t}\right]_{p}=(1-k)^{2} \operatorname{Var}\left[p_{t}\right]_{p}+s^{2}=\frac{2 s^{2}}{1+k}
$$


The difference between the unconditional variance of inflation under price level targeting and inflation targeting is

$$
\operatorname{Var}\left[\pi_{t}\right]_{p}-\operatorname{Var}\left[\pi_{t}\right]_{\pi}=\left(\frac{2}{1+k}-\frac{1}{1-h^{2}}\right) s^{2}=\frac{1-2 h^{2}-k}{\left(1-h^{2}\right)(1+k)} s^{2} .
$$

Hence,

$$
\operatorname{Var}\left[\pi_{t}\right]_{p}<\operatorname{Var}\left[\pi_{t}\right]_{\pi} \quad \text { if and only if } k>1-2 h^{2} .
$$

We see that if $h=k$, we have $\operatorname{Var}\left[\pi_{t}\right]_{p}<\operatorname{Var}\left[\pi_{t}\right]_{\pi}$ if and only if $h=k>\frac{1}{2}$.

Fischer (1994, Figure 2.4 and Footnote 45) compares (C.2) and (C.4) with $h=0$ and $k=0.5$, for which case $k<1-2 h^{2}$ and $\operatorname{Var}\left[\pi_{t}\right]_{p}=\frac{4}{3} s^{2}>\operatorname{Var}\left[\pi_{t}\right]_{\pi}=s^{2}$; the inflation variance is higher under price level targeting.

Duguay (1994) examines the processes (C.1) and (C.3) for different values of $h$ and $k$. Typical values used are $h=0.5$ and 0.7 (inflation targeting such that $75 \%$ of the adjustment of inflation towards the target is achieved in 2 and 4 periods (years), respectively), $k=0.7$ (price level targeting where $75 \%$ of the adjustment of the price level towards the target is achieved in 4 periods (years)), and $s^{2}=1$ (when $\pi$ and $p$ are measured in \%/year and \%, respectively, that is, scaled by 100). ${ }^{15}$ Let me use these values and compute the unconditional variance of inflation. For these values, $k>1-2 h^{2}$, the variance is less under price level targeting, and we get $\operatorname{Var}\left[\pi_{t}\right]_{\pi}=1.33$ and 1.95 , respectively, and $\operatorname{Var}\left[\pi_{t}\right]_{p}=1.18$. Now the variance of inflation is lower under price level targeting.

Duguay (1994) does not report this unconditional standard deviation of one-period inflation; instead he reports the conditional standard deviation of the price level and the average inflation rate, $\sqrt{\operatorname{Var}_{t} p_{T}}$ and $\sqrt{\operatorname{Var}_{t} \frac{P_{T}-p_{t}}{T-t}}=\frac{\sqrt{\operatorname{Var}_{t} P T}}{T-t}$, for different time horizons $T-t$. Tables $A 1$ and $A 2$ summarize some results for the processes (C.1) and (C.3).

What univariate processes for inflation and the price level do inflation targeting and price level targeting under discretion result in? Under inflation targeting (2.13) implies $l_{t}=\frac{1-\alpha \hat{b}}{\hat{b}}\left(\pi_{t}-\right.$ a). Using this in (2.14) results in

$$
\pi_{t}=(1-\rho) \hat{a}+\rho \pi_{t-1}+\hat{b} \epsilon_{t}
$$

Thus, disregarding the constant, inflation targeting corresponds to the process (C.1) with $h=\rho$. Under price level targeting (3.8) implies $l_{t}=\frac{1-\alpha \hat{b}}{\hat{b}}\left(p_{t}-\hat{a}_{t}\right)$. Using this in (2.14) gives

$$
\tilde{p}_{t}=\rho \tilde{p}_{t-1}+\hat{b} \epsilon_{t},
$$

\footnotetext{
${ }^{15}$ My notation differs from Duguay's. My $h$ is his $\beta$, and my $k$ is his $1-\alpha$.
} 
where $\tilde{p}_{t}=p_{t}-\hat{a}_{t}$. Thus, the process for $\tilde{p}_{t}$ corresponds to the process (C.3) with $k=\rho$. The corresponding inflation process will be

$$
\pi_{t}=\pi^{*}-(1-\rho)\left(p_{t-1}-\hat{a}_{t-1}\right)+\hat{b} \epsilon_{t} .
$$

Thus, for $h=k=\rho>\frac{1}{2}$ we get the result that $\operatorname{Var}\left[\pi_{t}\right]_{p}<\operatorname{Var}\left[\pi_{t}\right]_{\pi}$.

Table A1. Inflation targeting

(1) $\quad \pi_{t}=h \pi_{t-1}+\eta_{t}$

(2) $\quad \pi_{T}=h^{T-t} \pi_{t}+\sum_{\tau=t+1}^{T} h^{T-\tau} \eta_{\tau}$

(3) $\quad p_{T}=p_{t}+\sum_{\tau=t+1}^{T} \pi_{T}$

(4) $\operatorname{Var}_{t} \pi_{T}=\left(1-h^{2(T-t)}\right) \frac{s^{2}}{1-h^{2}}$

(5) $\quad \operatorname{Var}_{t} p_{T}=\left[(T-t)-2 \frac{1-h^{T-t}}{1-h} h+\frac{1-h^{2(T-t)}}{1-h^{2}} h^{2}\right] \frac{s^{2}}{(1-h)^{2}}$

(6) $\operatorname{Var}\left[\pi_{t}\right]_{\pi}=\frac{g^{2}}{1-h^{2}}$

(7) $\operatorname{Var}\left[p_{t}\right]_{\pi}=\infty$

Table A2. Price level targeting

(1) $\quad p_{t}=k p_{t-1}+\eta_{t}$

(2) $\quad \pi_{t}=-(1-k) p_{t-1}+\eta_{t}$

(3) $\quad p_{T}=k^{T-t} p_{t}+\sum_{\tau=t+1}^{T} k^{T-\tau} \eta_{\tau}$

(4) $\pi_{T}=-(1-k) p_{T-1}+\eta_{T}$

(5) $\quad \operatorname{Var}_{t} p_{T}=\left(1-k^{2(T-t)}\right) \frac{s^{2}}{1-k^{2}}$

(6) $\operatorname{Var}_{t} \pi_{t+1}=s^{2}$

(7) $\operatorname{Var}_{t} \pi_{T}=\left[(1-k)^{2}\left(1-k^{2(T-t-1)}\right)+1-k^{2}\right] \frac{s^{2}}{1-k^{2}} \quad(T \geq 2)$

(7) $\operatorname{Var}\left[p_{t}\right]_{p}=\frac{s^{2}}{1-k^{2}}$

(9) $\operatorname{Var}\left[\pi_{t}\right]_{p}=\frac{2 s^{2}}{1+k}$ 


\section{References}

Akerlof, George A., William T. Dickens, and George L. Perry (1966), "The Macroeconomics of Low Inflation," Brookings Papers on Economic Activity 1:1966, forthcoming.

Bank of Canada (1994), Economic Behavior and Policy Choice under Price Stability, Ottawa.

Bean, Charles R. (1983), "Targeting Nominal Income: An Appraisal," Economic Journal 93, 806-819.

Bryant, Ralph C., Peter Hooper and Catherine L. Mann, eds. (1993), Evaluating Policy Regimes, Brookings, Washington, D.C.

Crawford, Allan, and Chantal Dupasquier (1994), "Can Inflation Serve as a Lubricant for Market Equilibrium," in Bank of Canada, Economic Behavior and Policy Choice under Price Stability, Ottawa.

Duguay, Pierre (1994), "Some Thoughts on Price Stability versus Zero Inflation," Working Paper, Bank of Canada. Presented at the conference on Central Bank Independence and Accountability, Università Bocconi, Milan, March, 1994.

Einaudi, L. (1953), "The Theory of Imaginary Money from Charlemange to the French Revolution," in F.C. Lane and J.C. Riemersma, eds., Enterprise and Secular Change, Homewood, IIl., 229-261.

Fillon, Jean-François, and Robert Tetlow (1994), "Zero-Inflation or Price-Level Targeting? Some Answers from Stochastic Simulations on a Small Open Economy Macro Model," in Bank of Canada, Economic Behaviour and Policy Choice under Price Stability, Ottawa.

Fischer, Stanley (1994), "Modern Central Banking," in Forrest Capie, Charles Goodhart, Stanley Fischer and Norbert Schnadt, The Future of Central Banking, Cambridge University Press, Cambridge, U.K.

Fisher, Irving (1934), Stable Money. Published 1935 in Britain under the title of Stable Money: A History of the Movement, Allen \& Unwin, London.

Fuhrer, Jeffrey C., and Brian Madigan (1994), "Monetary Policy when Interest Rates are Bounded at Zero," Publication No. 393, Center for Economic Policy Research, Stanford University.

Gerlach, Stefan (1993), "Inflation Targets as Guideposts for Monetary Policy: Lessons from Exchange Rate Target Zones," Working Paper, BIS.

Goodhart, Charles A.E., and José Viñals (1994), "Strategy and Tactics of Monetary Policy: Examples from Europe and the Antipodes," in Jeffrey C. Fuhrer, ed., Goals, Guidelines and Constraints Facing Monetary Policymakers, Federal Reserve Bank of Boston.

Haldane, Andrew G., ed. (1995), Targeting Inflation, Bank of England, London.

Haldane, Andrew G. and Christopher K. Salmon (1995), "Three Issues on Inflation Targets: Some United Kingdom Evidence," in Haldane (1995), 170-201.

Hall, Robert E. (1984), "Monetary Strategy with an Elastic Price Standard," in Price Stability and Public Policy, Federal Reserve Bank of Kansas City, Kansas City, 137-159.

Hall, Robert E. (1986), "Optimal Monetary Institutions and Policy," in Colin D. Campbell and William R. Dougan, eds., Alternative Monetary Regimes, Johns Hopkins University Press, Baltimore, 224-239.

Hall, Robert E., and N. Gregory Mankiw (1994), "Nominal Income Targeting," in N. Gregory Mankiw, ed., Monetary Policy, University of Chicago Press, Chicago, 71-94. 
Henderson, Dale W., and Warwick J. McKibbin (1993), "A Comparison of Some Basic Monetary Policy Regimes for Open Economies: Implications of Different Degrees of Instrument Adjustment and Wage Persistence," Carnegie-Rochester Series on Public Policy 39, 221317.

Jonsson, Gunnar (1995), "Monetary Politics and Unemployment Persistence," in Gunnar Jonsson, Institutions and Incentives in Monetary and Fiscal Policy, IIES Monograph No. 29, chapter 4.

Jonung, L. (1979), "Kurt Wicksell's Norm of Price Stabilisation and Swedish Monetary Policy in the 1930s," Journal of Monetary Economics 5, 459-496.

King, Mervyn (1995), "Changes in UK Monetary Policy: Rules and Discretion in Practice," paper presented to the Swiss National Bank Conference on Rules versus Discretion in Monetary Policy, March 15-19, Gerzensee, Switzerland.

Konieczny, Jerzy D. (1994), "The Optimal Rate of Inflation: Competing Theories and Their Relevance to Canada," in Bank of Canada, Economic Behaviour and Policy Choice under Price Stability, Ottawa.

Laidler, David (1993), "Price Stability and the Monetary Order," in Kumihara Shigehara, ed., Price Stabilization in the 1990s, Macmillan, London, 331-356.

Lebos, David E. (1993), "Monetary Policy at Near Zero Interest Rates," Working Paper No. 136, Division of Research and Statistics, Federal Reserve Board.

Lebow, David E., John M. Roberts and David J. Stockton (1992), "Economic Performance under Price Stability," Working Paper No. 125, Division of Research and Statistics, Federal Reserve Board.

Lebow, David E. , David J. Stockton, and William L. Wascher (1994), "Inflation, Nominal Wage Rigidity, and the Efficiency of Labor Markets," Working Paper, Division of Research and Statistics, Federal Reserve Board.

Leiderman, Leonardo, and Lars E.O. Svensson, eds. (1995), Infiation Targets, CEPR, London.

Lockwood, Ben, and Apostolis Philippopoulos (1994), "Insider Power, Unemployment Dynamics and Multiple Inflation Equilibra," Economica 61, 59-77.

Lockwood, Ben, Marcus Miller and Lei Zhang (1995), "Designing Monetary Policy when Unemployment Persists," Working Paper, University of Exeter.

McCallum, Bennett T. (1990), "Targets, Indicators, and Instruments of Monetary Policy," in William S. Haraf and Phillip Cagan, Monetary Policy for a Changing Financial Environment, The AEI Press, Washington, D.C., Chapter 3.

Persson, Torsten, and Guido Tabellini (1990), Macroeconomic Policy, Credibility and Politics, Harwood, London.

Persson, Torsten, and Guido Tabellini (1993), "Designing Institutions for Monetary Stability," Carnegie-Rochester Conference Series on Public Policy 39, 53-84.

Rogoff, Kenneth (1985), "The Optimal Degree of Commitment to a Monetary Target," Quarterly Journal of Economics 100, 1169-1190.

Scarth, William (1994), "Zero Inflation versus Price Stability," in Bank of Canada, Economic Behaviour and Policy Choice under Price Stability, Ottawa.

Summers, Lawrence H. (1991), "How Should Long-Term Monetary Policy Be Determined?" Journal of Money, Credit and Banking 23, 625-631.

Svensson, Lars E.O. (1996), “Optimal Inflation Targets, 'Conservative Central Banks' and Linear Inflation Contracts," revision of NBER Working Paper No. 5251. 
Taylor, John B. (1994), "Discretion versus Policy Rules in Practice," Carnegie-Rochester Conference Series on Public Policy 39, 195-214.

Walsh, Carl (1986), "In Defense of Base Drift," American Economic Review 76, 692-700.

Walsh, Carl (1995), "Optimal Contracts for Independent Central Bankers," American Economic Review 85, 150-167. 
To order any of these papers, see instructions at the end of the list. To subscribe to all NBER Working Papers or the papers in a single area, see instructions inside the back cover. A complete list of NBER Working Papers and Reprints can be accessed on the Internet by using our gopher at nber.harvard.edu or our World Wide Web site at http://nber.harvard.edu/.

Number

5668

5669
Author(s)

Frank Lichtenberg Bruno van Pottelsberghe de la Potterie

John Cawley

Tomas Philipson

Fukunari Kimura

Robert E. Baldwin

Owen Lamont

Edward P. Lazear

Pinelopi Koujianou Goldberg

Michael Kremer

Charles Morcom

Robert E. Cumby

Matthew B. Canzoneri

Robert E. Cumby

Behzad Diba

James M. Poterba

Fernando Alvarez

Andrew Atkeson

Lawrence F. Katz

Kala Krishna

John Morgan

Barry Eichengreen

Andrew K. Rose

Charles Wyplosz

B. Douglas Bernheim Lee Redding
Title

$\underline{\text { Date }}$

International R\&D Spillovers: A

$7 / 96$

Re-Examination

An Empirical Examination of Information

$7 / 96$

Barriers to Trade in Insurance

Application of Nationality-Adjusted

$7 / 96$

Net Sales and Value Added Framework:

The Case of Japan

Earnings and Expected Returns

$7 / 96$

Performance Pay and Productivity

$7 / 96$

The Effects of the Corporate Average $\quad 7 / 96$

Fuel Efficiency Standards

Elephants

$7 / 96$

Forecasting Exchange Rates and Relative

$7 / 96$

Prices With the Hamburger Standard: Is

What You Want What You Get With McParity?

Relative Labor Productivity and the Real

Exchange Rate in the Long Run: Evidence

for a Panel of OECD Countries

Demographic Structure and the Political

$7 / 96$

Economy of Public Education

Money and Exchange Rates in the

$7 / 96$

Grossman-Weiss-Rotemberg Model

Wage Subsidies for the Disadvantaged

$7 / 96$

Implementing Results-Oriented Trade

$7 / 96$

Policies: The Case of the US-Japanese Auto

Parts Dispute

Contagious Currency Crises

$7 / 96$

Optimal Money Burning: Theory and 
To order any of these papers, see instructions at the end of the list. To subscribe to all NBER Working Papers or the papers in a single area, see instructions inside the back cover. A complete list of NBER Working Papers and Reprints can be accessed on the Internet by using our gopher at nber.harvard.edu or our World Wide Web site at http://nber.harvard.edu/.

Number

5683

5684

5685

5686

5687

5688

5689

5690

5691

5692

5693

5694

5695

5696

5697
Author(s)

Kevin A. Hassett

R. Glenn Hubbard

Michael Woodford

John Bound

Harry J. Holzer

R. Glenn Hubbard

Jonathan S. Skinner

David Card

Christopher J. Ruhm

Jean O. Lanjouw

Josh Lerner

Jeff Dominitz

Charles F. Manski

Russell Cooper

Alok Johri

Christina D. Romer

David H. Romer

Donald R. Davis

Alberto Alesina

Enrico Splaore

Barbara J. Spencer

James R. Markusen Anthony J. Venables Denise Eby Konan Kevin H. Zhang

Kiminori Matsuyama $\underline{\text { Title }}$

Date

Tax Policy and Investment

$7 / 96$

Control of the Public Debt: A Requirement for Price Stability?

$7 / 96$

Demand Shifts, Population Adjustments, and Labor Market Outcomes during the 1980s

Assessing the Effectiveness of Saving

$7 / 96$

Incentives

Deregulation and Labor Earnings in the Airline Industry

The Economic Consequences of Parental Leave Mandates: Lessons From Europe

Preliminary Injunctive Relief: Theory and Evidence from Patent Litigation

Perceptions of Economic Insecurity: Evidence from the Survey of Economic Expectations

Dynamic Complementarities: A Quantitative Analysis

Federal Reserve Private Information and the Behavior of Interest Rates

Trade Liberalization and Income Distribution

$8 / 96$

International Conflict, Defense Spending and $8 / 96$ the Size of Countries

Quota Licenses for Imported Capital

Equipment: Could Bureaucrats Ever Do Better Than the Market?

A Unified Treatment of Horizontal Direct $8 / 96$ Investment, Vertical Direct Investment, and the Pattern of Trade in Goods and Services

Why Are There Rich and Poor Countries?: 
To order any of these papers, see instructions at the end of the list. To subscribe to all NBER Working Papers or the papers in a single area, see instructions inside the back cover. A complete list of NBER Working Papers and Reprints can be accessed on the Internet by using our gopher at nber.harvard.edu or our World Wide Web site at http://nber.harvard.edu/.

$\begin{array}{ll}\text { Number } & \text { Author(s) } \\ 5698 & \text { Robert J. Barro } \\ 5699 & \text { Anna J. Schwartz } \\ 5700 & \begin{array}{l}\text { Jeffrey A. Frankel } \\ \text { Andrew K. Rose }\end{array} \\ 5701 & \begin{array}{l}\text { David Card } \\ \text { Philip K. Robins }\end{array}\end{array}$

5702

5703

5704

5705

5706

5707

5708

5709

5710

5711
Kym Anderson

Lawrence J. Christiano Sharon G. Harrison

Herschel I. Grossman Minseong Kim

Robert Gibbons

Donald R. Davis

David E. Weinstein

Olivia Mitchell

Jan Olson

Thomas Steinmeier

David Card

Alan Krueger

Menzie Chinn

Louis Johnston

Michael D. Bordo

Anna J. Schwartz

Armen Hovakimian

Edward J. Kane $\underline{\text { Title }} \quad \underline{\text { Date }}$

Determinants of Economic Growth: A $\quad 8 / 96$

Cross-Country Empirical Study

From Obscurity to Notoriety: A Biography

$8 / 96$

of the Exchange Stabilization Fund

The Endogeneity of the Optimum

Currency Area Criteria

Do Financial Incentives Encourage Welfare

Recipients to Work? Evidence from a

Randomized Evaluation of the

Self-Sufficiency Project

Social Policy Dimensions of Economic

$8 / 96$

Integration: Environmental and

Labour Standards

Chaos, Sunspots, and Automatic

$8 / 96$

Stabilizers

Inequality, Predation, and Welfare

$8 / 96$

Incentives and Careers in Organizations

$8 / 96$

Does Economic Geography Matter for International Specialization?

$8 / 96$

Construction of the Earnings and Benefits

$8 / 96$

File (EBF) for Use With the Health and

Retirement Survey

School Resources and Student Outcomes:

$8 / 96$

An Overview of the Literature and New

Evidence from North and South Carolina

Real Exchange Rate Levels, Productivity

$8 / 96$

and Demand Shocks: Evidence from a Panel of 14 Countries

Why Clashes Between Internal and External

$8 / 96$

Stability Goals End in Currency Crises,

1797-1994

Risk-Shifting by Federally Insured

$8 / 96$ 
To order any of these papers, see instructions at the end of the list. To subscribe to all NBER Working Papers or the papers in a single area, see instructions inside the back cover. A complete list of NBER Working Papers and Reprints can be accessed on the Internet by using our gopher at nber.harvard.edu or our World Wide Web site at http://nber.harvard.edu/.

Number

5712

5713

5714

5715

5716
Author(s)

Adam B. Jaffe Manuel Trajtenberg

Michael Grossman Frank J. Chaloupka Charles C. Brown

Jeffrey A. Frankel

Sergio L. Schmukler

Sofronis Clerides

Saul Lach

James Tybout

Jennifer Hunt

Fiona Scott Morton

Michael Kremer

Eric Maskin

Lars E. O. Svensson
Title

Flows of Knowledge from Universities and

Federal Labs: Modeling the Flow of Patent

Citations Over Time and Across

Institutional and Geographic Boundaries

The Demand for Cocaine by Young Adults:

A Rational Addiction Approach

Country Fund Discounts, Asymmetric

Information and the Mexican Crisis of 1994:

Did Local Residents Turn Pessimistic

Before International Investors?

Is "Learning-by-Exporting" Important?

Micro-dynamic Evidence from Colombia,

Mexico and Morocco

The Response of Wages and Actual Hours

Worked to the Reduction of Standard Hours in Germany

The Strategic Response by Pharmaceutical

Firms to the Medicaid Most-Favored-

Customer Rules

Wage Inequality and Segregation by Skill

Price Level Targeting vs. Inflation

Targeting: A Free Lunch?
$8 / 96$

$8 / 96$

$8 / 96$

Date

$8 / 96$

$8 / 96$

$8 / 96$

$8 / 96$

$8 / 96$

Copies of the above working papers can be obtained by sending $\$ 5.00$ per copy (plus $\$ 10.00$ per order for postage and handling for all locations outside the continental U.S.) to Working Papers, NBER, 1050 Massachusetts Avenue, Cambridge, MA 02138-5398. Advance payment is required on all orders. Payment may be made by check or credit card. Checks should be made payable to the NBER and must be in dollars drawn on a U.S. bank. If paying by credit card, include the cardholder's name, account number and expiration date. For all mail orders, please be sure to include your return address and telephone number. Working papers may also be ordered by telephone (617-868-3900), by fax (617-868-2742), or by email at orders@nber.harvard.edu. 